\title{
Price Elasticity of Demand on the High-Speed Rail Lines of Spain Impact of the New Pricing Scheme
}

\author{
Alejandro Ortega Hortelano, Andres Felipe Guzman, \\ John Preston, and Jose Manuel Vassallo
}

Reduced travel time, regional cohesion, economic development, and environmental benefits were some of the reasons given to develop a high-speed rail (HSR) network in Spain. Since the first high-speed line in Spain opened in 1992, HSR has been a part of the travel experience, despite recent concerns raised about the lack of demand and low occupancy rates of HSR trains compared with those in other countries. In February 2013, Renfe Operadora, Spain's state-owned transport company, implemented a new pricing scheme, which reduced ticket prices by at least $11 \%$ and introduced flexibility in their purchase. In this research, the effects of the new scheme were analyzed, and the impact on the shift in transport modes was substantiated through consideration of a discrete choice model. As a consequence of this policy, occupancy rates were increased hugely. Although apparently ticket price was not regarded by users as the main reason to travel by HSR, the price elasticity of demand turned out to be high. Given the transport modes that competed with HSR, the effects were quite different. For short routes connecting small- and medium-sized cities with big metropolitan areas, growth in demand was achieved at the expense of the car and the bus, whereas for long routes connecting large cities in which air transport was available, the growth occurred mainly at the expense of air transportation, and induced demand also was triggered. Finally, when the owner of the infrastructure and the train operating companies were managed by the government, the rail infrastructure fee policy set may have prompted unfair competition with other transport modes.

High-speed rail (HSR) has been the means of transportation in which the Government of Spain has invested the most by far: more than $€ 45$ billion over the past two decades. The first HSR line in the country was inaugurated in 1992 and linked Madrid with Seville, the country's fourth largest city. Seville had been elected to host the 1992 Expo World's Fair and, through this investment, the economy of Spain's southern region was expected to be stimulated. After the first project, Spain continued to build new HSR lines and now has the largest HSR network in Europe. With 3,100 km in service- which is expected to grow to $5,000 \mathrm{~km}$ in the near future-Spain's network is the second largest in the world after China's.

The HSR lines in Spain, known as Alta Velocidad Española (AVE), are prestigious. Because the punctuality of the trains is almost $99 \%$, the lines have helped to promote regional cohesion and economic development and to provide an environmentally friendly transport mode. As an indication of the remarkable know-how and experience gained from the development of Spain's HSR, a consortium headed by Spanish companies, in conjunction with two Saudi Arabian companies ( $88 \%$ of whose shareholders are Spanish), was selected to undertake an investment of about $€ 7$ billion in the high-speed (HS) trains and superstructures from Medina, Saudi Arabia, to Mecca, Saudi Arabia.

However, HSR also has its disadvantages, such as the huge investment necessary to build the infrastructure, the high maintenance costs, and the low demand in many corridors that can make it difficult to justify some lines from a socioeconomic point of view (1). In fact, according to the Spanish Minister of Transport, some of the lines in Spain had an occupancy rate below 50\% in 2012 (2). By the beginning of 2013, the Spanish government decided to implement a more flexible pricing policy, as well as an overall price reduction for every kind of ticket, aimed at improving the occupancy rate of HS trains. This pricing scheme was similar to the yield management technique used for airplanes, which sets the price depending on the hour of the day, the category of the user (e.g., first class, tourist), the demand expected, and how far in advance the booking is made (3).

The goal of the study reported in this paper was to examine the effects that the reduction in prices had on HSR demand and, where possible, on the Spanish transport system. The remainder of this paper is organized as follows. The second section provides a review of the literature on aspects that influence the demand for HSR compared with that of other transport modes. The third section describes and analyzes a case study of the Spanish HSR pricing policy, including a discrete choice model developed on the basis of a survey conducted in 2014 to substantiate the results. Finally, the fourth section discusses the key findings from this analysis and points out potential policy implications.

\section{LITERATURE REVIEW}

It is broadly acknowledged that HS trains run at a speed above $250 \mathrm{~km} / \mathrm{h}$ to offer high capacity and, in some corridors, high frequency. HSR also is regarded as an environmentally friendly alternative to travel by air and by car to reach destinations within a medium-range distance. Albalate and Bel found the distance between the railway 
nodes to be a key factor that influenced success (4). In addition, HSR can replace conventional railway trains in corridors in which higher capacity and less travel time is needed, which improves the railway service, even at the expense of other modes for which HSR is substituted. Nevertheless, some researchers have pointed out that the investment in HSR is high and cannot be justified on the basis of its economic benefits, because they are not certain (5), even though HSR has been shown to produce good economic returns in some instances and in rare cases could even be commercially viable ( 6 ). Indeed, de Rus confirmed that significant demand was needed to justify investment in HSR from the perspective of cost-benefit analysis (7). In the case of Spain, spatial equity was the main reason to promote HSR. In 2005, the president of the government declared that all capitals of Spain's provinces should be linked by HSR so that travel times would be no longer than $4 \mathrm{~h}$ from the country's capital, Madrid. Unfortunately, no debate occurred on the political scene about the social return on HSR investment, because HSR was considered a symbol of modernity, enjoyed the support of the public, and tickets were subsidized (8). The consensus was that the government should avoid excess charges, which could reduce the social benefits of a new HSR line through a reduction in traffic and a smaller market share than air transportation (9). In the United Kingdom, despite huge transport benefits to accrue mainly to existing and future rail users, a subsidy from the government would be needed in addition to the HSR's planned coverage of operating and maintenance costs (10). The development of a new HSR line also may be an opportunity to improve decision-making processes, not only for railway infrastructure but for every kind of transport infrastructure (11).

The academic literature on HSR is vast and diverse. Generally speaking, studies about the effects of HSR can be divided between ex ante and ex post interventions. The first group of studies was quite optimistic, whereas the second group identified benefits and costs in a more realistic manner (12). The gains from HSR were larger in the first cities to be connected, but some small cities also experienced important transformations, particularly in cases in which additional investments from the public sector were implemented. However, Monzón et al. remarked that the accessibility gains were more notable in urban areas with an HSR station, while other locations received limited benefit (i.e., the bypass problem), and therefore spatial equity issues could arise (13). To avoid such imbalances, Bröcker et al. recommended consideration of network efficiency and spatial equity issues in the HSR planning process (14). In other words, the benefits from HSR are not universal and depend on the case study, because transport is a necessary but not sufficient condition for the development of cities (15).

Competition between HSR and other transport modes, particularly air transport, has also been studied widely. Strong competition between air transport and HSR was found to occur on routes with distances up to $1,000 \mathrm{~km}$ (16), but was most likely to occur between 400 and $800 \mathrm{~km}$ (17). Several parameters are important in the assessment of competition. For instance, Dobruszkes found that, in addition to travel time, other variables may affect competition, including frequencies, fares, airline hubs, and geographical structures of urban regions (18). Pagliara et al. noted that prices and frequency were among the most important variables to explain HSR demand from competing modes, and check-in and security controls negatively affected airplane demand (19). For the London-Paris route, travel time and frequency were found to be the two main keys of travel behavior (20).

Clewlow et al. found that improvements in HSR travel time led to a reduction in short-distance air trips (21). In addition, urban structures were shown to have an important influence on modal share.
Albalate et al. found a reduction in the number of seats offered by airlines, albeit flight frequencies were not expected to undergo a significant reduction (i.e., switch to smaller planes) (22). Rail-air agreements also can bring commercial and environmental benefits, but under some circumstances the agreements can raise competition concerns from a legal perspective (23).

The role that HSR plays in tourism has been studied, with some differences found across European capitals. Whereas HSR was considered one of the reasons that tourists visited Paris, its presence did not have the same effect either in Madrid or in Rome $(24,25)$. Competition between HSR and conventional trains was analyzed in Taiwan, where the pricing strategy was a determinant factor in profit and welfare (26).

Usually, HSR is highly regulated and, unlike airlines, price discrimination is hardly ever practiced (Eurostar and the current competitive situation in Italy are exceptions). Given that profile, Yang and Zhang developed a model that assumed that airlines aimed to maximize their profit, while HSR aimed to maximize a weighted sum of profit and social welfare (27). The profit of air transport was found to be higher under price discrimination than with uniform pricing, whereas the profit for HSR remained unchanged, even though the welfare could vary. In research conducted in the United Kingdom, Harvey et al. found that willingness to pay for travel time reductions also was related to prestige and comfort (28).

With respect to ticketing preference, Cheng and Huang found that perceived benefits, perceived sacrifice, and perceived ease of use were critical factors that influenced passengers' retail channel preference (29). Moreover, they also found differences with respect to demographic factors, trip characteristics, and how far in advance the ticket was bought.

Finally, all over Europe, railway infrastructure belongs to the government, and the service is provided mostly by public companies, which have to pay an annual fee to use the railway track. According to the European regulation (i.e., Fourth Package), railway infrastructure should be opened to all qualified operators in the near future. Thus, train operating companies are looking for decision-support tools in the areas of pricing, yield management, schedule planning, and control to capture new users or retain existing ones (30).

For instance in April 2012, Italy adopted the European regulation with an increase in HSR demand and train supply, albeit the results for the private operator were not so positive (31). The recent pricing experience in Spain appears to be an important example of yield management in HSR and thus constitutes a case study of interest to policy makers and regions about new HSR developments. The main objective of the research reported here was to analyze this case study and to explain the impacts of the new pricing policy on other transport modes and on HSR demand. Therefore, transport demand was studied in some corridors with HSR, and a discrete choice model was developed to focus on the reasons that users chose HSR and the price elasticity of demand.

\section{CASE STUDY}

\section{Passenger Transport in Spain}

Domestic passenger transport in Spain is dominated by the road mode, with more than $90 \%$ of the share over the past 5 years. This high value was encouraged by the vast highway network developed over the past two decades. In 2013, Spain had 15,100 km (7,007 mi) of modern high-capacity roads (32). The role of road transport in 
the international market (i.e., travelers from abroad) has become less important in recent years, and decreased from a share of $51 \%$ to $44 \%$, while air transport increased from $46 \%$ to $53 \%$.

Rail and air transportation have not been able to threaten the dominance of the road for domestic transport use, despite the fact that passenger rail share slightly increased from $5.2 \%$ in 2009 to $6.0 \%$ in 2013. Inland waterway transportation within Spain is low compared with that of other countries in the European Union. Rail transportation plays an almost negligible role at the international level (less than $0.2 \%$ ). Thus the goal of HSR investment in Spain was not to turn the Spanish transport modal share inside out, but rather to change the modal share in specific, point-to-point relationships.

\section{HSR Transport System in Spain}

After Spain joined the European Union in 1986, it took advantage of European funds and its own economic growth to develop an HSR network. Indeed, in 1987 the country's railway transport planners considered an increase in maximum rail speed from 160 to $220 \mathrm{~km} / \mathrm{h}$ and, in 1988, the government resolved to build the first HSR line (Madrid to Seville).

This first HSR line was constructed according to the technical standards of the French high-speed network (i.e., Train à Grande Vitesse) with a gage of $1,435 \mathrm{~mm}$. The line entered into service in April 1992 and initially linked Madrid and Seville with a travel time of $2 \mathrm{~h}$ and $55 \mathrm{~min}$ rather than the $7 \mathrm{~h}$ formerly required. The infrastructure also connected the intermediate cities of Ciudad Real, Puertollano, and Cordoba. One year later, the commercial speed was increased up to $300 \mathrm{~km} / \mathrm{h}$, and the travel time was reduced to less than $2 \mathrm{~h}$ and $30 \mathrm{~min}$. The effects on the transport system on that corridor were large: the share of train use rose from $14 \%$ to more than $43 \%$, mainly at the expense of the airplane, and through the capture of additional users as well (33). The next step in the HSR network was to connect Madrid with Barcelona, the second largest city in Spain, located in the northeast corridor. The construction of two HSR lines, which consisted of Madrid-Zaragoza-Barcelona-French border and of Madrid-Valladolid, began in 1997 and 2002, respectively.

In 2003, the Madrid-Zaragoza stretch was opened at a reduced speed of $200 \mathrm{~km} / \mathrm{h}$ because of the lack of the European signaling system, known by its acronym ERTMS. In 2006, with the ERTMS, the commercial speed was increased to $250 \mathrm{~km} / \mathrm{h}$. Only 1 year later, in August 2007, there was a new increment to $300 \mathrm{~km} / \mathrm{h}$. By the end of that year, two new stretches entered into service: Madrid-Valladolid and Cordoba-Malaga in the northwest and southern corridor, respectively. In February 2008, HSR between Madrid and Barcelona was inaugurated. Again, the effect on competition with the airlines was enormous. HSR increased the market share of trains on that route from $12 \%$ to $47 \%$, and reduced the share of the airlines to $53 \%$. In December 2010, the connection between Madrid and Valencia, the third most populous city in Spain, entered into service, with a reduction in travel time by train from $7 \mathrm{~h}$ to $1 \mathrm{~h}$ and $35 \mathrm{~min}$. In this origindestination pair, the modal share of the train grew from $12 \%$ to $46 \%$. The share of air and bus transportation went down from $17.4 \%$ and $9.2 \%$ to $2.6 \%$ and $3.1 \%$, respectively. This HSR line also connected small cities such as Cuenca and Albacete to Madrid. Finally, in 2011, the speed for the Madrid-Barcelona segment was increased to $310 \mathrm{~km} / \mathrm{h}$. Other milestones were added after 2011, such as the Albacete-Alicante stretch, which opened in June 2013. However, for the purpose of this research, the focus was on the main lines and cities shown in Figure 1, given that the new pricing scheme was approved in February 2013, and therefore no data were available to compare the effect of the new ticket price with the previous situation on the new lines.

By 2012, 20 years after the inauguration of the first HSR line, more than 300 HS trains ran every day on Spanish HSR tracks, served nearly 100,000 passengers, and reached 80 Spanish municipalities.

\section{New Pricing Scheme and Demand Analysis in HSR Corridors}

In Spain, Renfe Operadora is the public transport operator company, and ADIF is the public company that owns and manages the HSR network. At the inception of HSR, Renfe Operadora set fixed prices, which depended only on the class and type of train. Discount prices were implemented years later, but the approach was still far away from the yield management pricing techniques used by airlines (3). Renfe Operadora wanted to go further. In February 2013, it introduced more flexibility as well as generalized ticket price reductions aimed at improving the occupancy rate of HS trains. The main characteristics of the plan can be summarized as follows:

- Average reduction of single ticket price by $11 \%$. If the trip was longer than $650 \mathrm{~km}$, the reduction was even greater. This reduction applied to HS trains without the category of public service (i.e., Alvia train at $250 \mathrm{~km} / \mathrm{h}$, AVE train above $300 \mathrm{~km} / \mathrm{h}$ ). The AVANT trains under public service were cheaper, because they received a subsidy, and their maximum speed was $250 \mathrm{~km} / \mathrm{h}$.

- Promotional ticket with a reduction up to $70 \%$ of the single ticket price. The discount depended on the expected demand and how far in advance the booking was made. The main disadvantage of this ticket was that cancellations and changes were allowed but at a higher price than in other categories. This tariff was similar but not the same as the yield management technique used by airlines. Prices changed on a daily basis. Thus this approach was not as dynamic as that of airline tickets. Moreover, when a season peak was expected, Renfe Operadora usually launched special promotions with a high number of tickets that fell within this category.

- Bonus for 10 trips between two cities, which could be used within 4 months after acquisition. The discount applied was $35 \%$ with respect to the single ticket price.

- Annual youth card for people between 14 and 26 years of age. Discounts above $30 \%$ of the single ticket price were offered.

- As in previous years, return trips were discounted at $20 \%$ of the single ticket price.

One of the reasons why Renfe Operadora is so popular with its users is its commitment to punctuality, implemented at the very beginning of HSR. If a train arrives 15 min late, Renfe Operadora will reimburse $50 \%$ of the ticket price. If the delay is more than $30 \mathrm{~min}$, Renfe Operadora will reimburse the whole ticket price. This commitment is even more stringent on the first line (i.e., Madrid-Seville) on which the reimbursement of the whole ticket is triggered by a delay of more than $5 \mathrm{~min}$.

Although the Spanish gross domestic product went down by $0.8 \%$ the year after the introduction of the new pricing scheme, revenue increased by $6.7 \%$, and the average occupancy rate of HS trains rose from $66 \%$ to $74.3 \%$. Thus Renfe Operadora met its initial objective to boost demand and increase travelers by train. The results for the main lines are summarized in Table 1. 


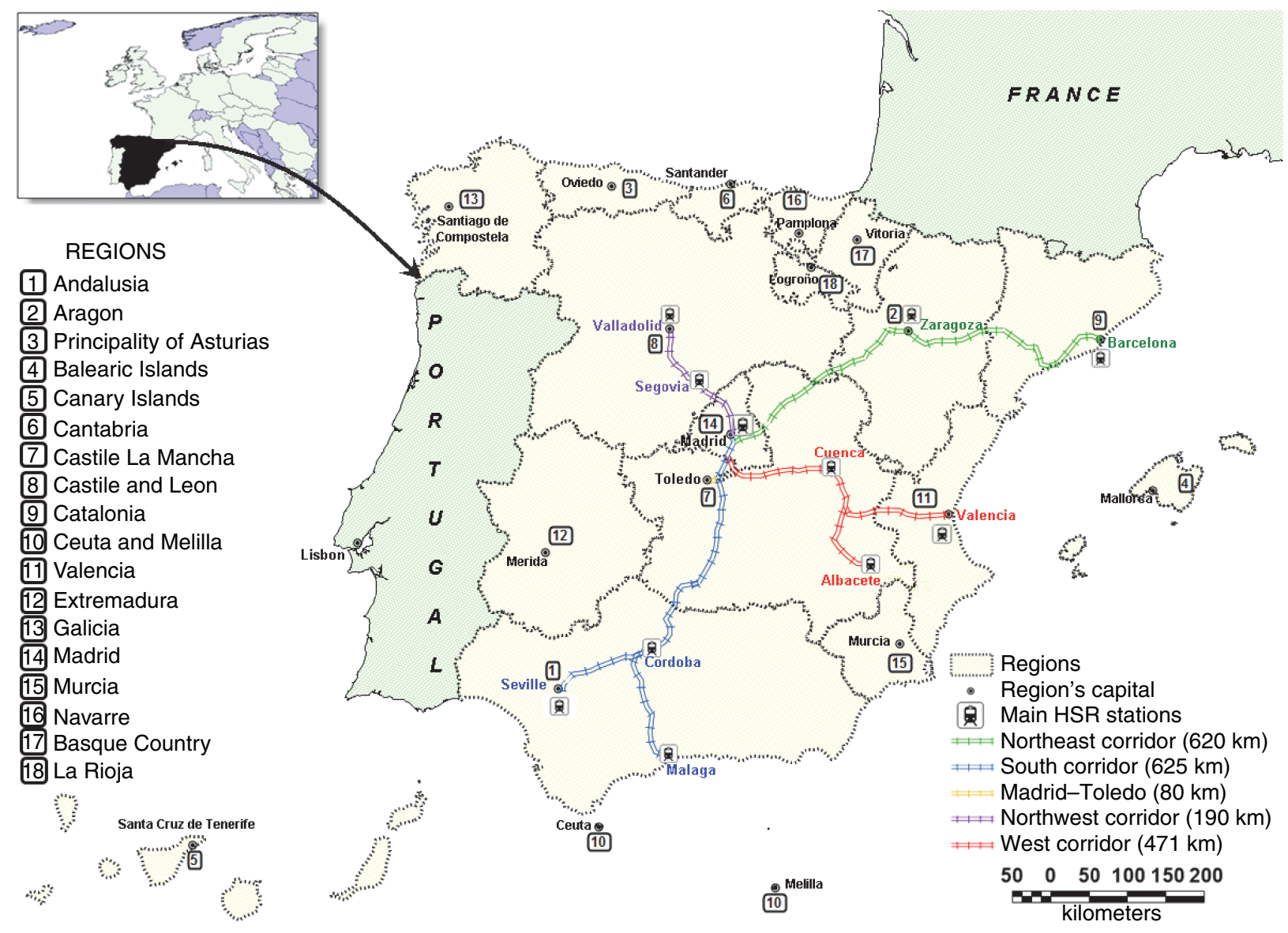

FIGURE 1 HSR corridors.

TABLE 1 HSR and Airplane Demand Changes After 1 Year of New Pricing Scheme

\begin{tabular}{llccc}
\hline Corridor & Services & $\begin{array}{l}\text { Surface } \\
\text { Distance (km) }\end{array}$ & $\begin{array}{c}\text { HSR Demand } \\
\text { Variation (\%) }\end{array}$ & $\begin{array}{c}\text { Airplane Demand } \\
\text { Variation (\%) }\end{array}$ \\
\hline Northeast & Madrid-Barcelona (B, C, A) & 621 & +16.0 & -14 \\
& Madrid-Zaragoza (B, C) & 307 & +10.0 & na \\
& Zaragoza-Barcelona (B, C) & 314 & +9.6 & na \\
South & Madrid-Seville (B, C, A) & 472 & +8.2 & -32 \\
& Madrid-Cordoba (B, C) & 344 & +9.0 & na \\
\multirow{2}{*}{ Madrid-Toledo } & Madrid-Malaga (B, C, A) & 500 & +9.5 & -30.7 \\
Northwest & Madrid-Toledo (B, C) & 80 & -1.2 & na \\
\multirow{2}{*}{ West } & Madrid-Segovia (B, C) & 90 & -4.8 & na \\
& Madrid-Valladolid (B, C) & & na \\
& Madrid-Valencia (B, C, A) & 400 & +3.4 & -3.7 \\
Long-distance & Madrid-Cuenca (B, C) & 195 & +7.4 & na \\
journeys & Madrid-Albacete (B, C) & 321 & +12.0 & -18 \\
\hline
\end{tabular}

NotE: B, C, A = bus, car, and air transportation available; $\mathrm{B}, \mathrm{C}=$ bus and car transportation available; na $=$ not applicable.

${ }^{a}$ AVANT trains are available. 
Two main conclusions arise from Table 1. First, growth in demand was outstanding. Second, this increase differed across origindestination pairs. Therefore, the trips were classified according to the distance traveled and the competing transport modes, as described in the sections that follow.

\section{Distances Less Than $100 \mathrm{~km}$}

In this kind of corridor, three transport modes competed: bus, HSR, and car. The route linked small and big cities, and the total travel time usually was less than $1 \mathrm{~h}$. The two origin-destination pairs in this category were Madrid-Segovia and Madrid-Toledo. Many users of these routes either were commuters, who lived outside Madrid but worked in Madrid, or they were tourists. The pricing scheme was not reflected in an appreciable way, because most of these users were eligible to take the public service trains (i.e., AVANT trains), which always charged the same, cheaper price. In Segovia, a shift occurred from use of the AVE and Alvia trains to use of the AVANT trains, which had a total growth in the corridor of about $2 \%$. In Toledo, only AVANT trains were available. The economies of Segovia and Toledo depend heavily on tourism. Thus the difference in the train demand growth could be explained by revenue per available room, which decreased in Toledo by $10.9 \%$ and increased in Segovia by $4.4 \%$. In other words, the price elasticity of this kind of corridor was low, and trips relied greatly on growth in the gross domestic product.

\section{Distances Between 150 and 400 km Without Airplanes}

This kind of corridor linked small and medium-sized cities, with the exception of Zaragoza, which was a medium-to-large city of about 650 thousand inhabitants. Again, three transport modes-bus, car, and HSR - competed for passengers. The reduction in use of the Madrid-Valladolid route was a result of the AVANT trains in the corridor. As with Segovia, a shift in use from AVE and Alvia to AVANT trains occurred, whose use grew by $2.5 \%$, while total growth in the corridor was $0.5 \%$. In fact, since the introduction of AVANT trains in 2009, this shift has continued at a steady pace. Thus in corridors in which public service was available, the reduction of ticket prices seemed to be negligible, because users tended to prefer to travel on the public service trains, given their cheaper and invariable price. Travel time on AVANT trains was only 5 min longer than it was on AVE trains, and it was the same as it was on the Alvia trains.

The huge growth in the use of the Albacete-Madrid trip route could have been influenced by the fact that other kinds of trains from Madrid offered a longer distance and travel time at a cheaper price were still running, and therefore a shift of users from those trains could have occurred. With respect to the other modes, HSR growth in this corridor was at the expense of car and bus users. No additional demand was recorded in these corridors.

\section{Distances Beyond $350 \mathrm{~km}$ with Airplanes}

This kind of corridor connected large cities with metropolitan areas with more than 1.5 million inhabitants. In these origin-destination pairs, HSR mostly competed with air transportation. With respect to the rail-air market alone, the share of HS trains was about $80 \%$, while the share of airplanes was about $20 \%$. The ticket price reduction increased the share of HS trains, reduced the share of air transportation, and prompted induced demand in the corridor.

The Madrid-Barcelona corridor opened in 2008, and competition between air and AVE has been fierce ever since. In 2012, HSR transported more users than airplanes did (2.688 million users versus 2.573 million users). The growth of AVE demand in the MadridBarcelona corridor was mainly at the expense of airplane use, while new users also were induced. Whereas travel by car and bus went down slightly by $1.2 \%$ and $3 \%$, after the yield management price was implemented, it did not have the same effect on airplane and HSR travel. HSR use increased by $16 \%$, while airplane use decreased by $14 \%$. Despite the economic recession, the total travelers in the corridor increased by $0.5 \%$. This kind of corridor was the only one in which, despite the economic recession, overall demand ultimately grew.

\section{Long-Distance Journeys}

For the two trips in this category, the in-vehicle travel time by airplane was about $1 \mathrm{~h}$ and $30 \mathrm{~min}$, whereas by HSR it was $5 \mathrm{~h}$ and $30 \mathrm{~min}$. The effect of the new pricing scheme was enormous, given that the huge increase in demand was at the expense of airlines. In this case the total demand in the corridor went down substantially.

As explained, the pricing scheme had a huge impact on other transportation modes. In particular, the airplane and the bus endured a decline from the shift in passengers to HSR and from the economic downturn. In fact, in some corridors HS trains were found to be cheaper than bus service. After a complaint made by bus companies, which were subject to taxes and special fees, and several conversations with air companies (34), Renfe Operadora decided to keep the same prices as in the previous year to fairly compete with other transportation modes (35). Indeed, the Spanish Court of Auditors recognized that the annual fees paid by Renfe Operadora to ADIF covered only about $50 \%$ of total infrastructure cost, albeit maintenance costs were covered completely.

\section{Effects of Yield Management Pricing Policy}

\section{Methodology}

The study of the choices that consumers make when confronted with alternatives is of the utmost importance. In the transportation field, the individual preferences of consumers, and the distribution of these preferences across the population, have been widely taken into account through the consideration of discrete choice models.

Discrete choice models have been developed and applied in disaggregated analysis of travel choice behavior since the beginning of the 1970s. In fact, progress toward a better understanding of transportation mode choice was made by several researchers, such as Domencich and McFadden (36) and McFadden (37). As a result, discrete choice models have been applied to describe the behavior of consumers when faced with a variety of mutually exclusive choices (38).

Discrete choice modeling assumes that the utility of each alternative is probabilistic, with error terms that follow the Gumbel distribution. The best-known probabilistic discrete choice model is the logit model, because it provides a convenient representation of the degree of heterogeneity of consumer tastes of the existing models of product differentiation. As pointed out, the underlying force 
that drives implementation of a yield management pricing policy in the context of demand levels is the price. This section examines through a discrete choice modeling to what extent the new pricing policy implemented made a difference in the HSR passenger transport segment.

\section{Revealed and Stated Preferences Surveys}

To meet the objectives of this research, a comprehensive database needed to be developed. Two types of data collection were conducted to identify $(a)$ why certain choices were made by travelers through revealed preference (RP) surveys and (b) how respondents' choices varied under different hypothetical situations through stated preference (SP) analyses.

As part of a research project developed in 2014, a survey was conducted to determine the reasons why passengers made their journey (e.g., origin, destination, travel time, cost, income), and to understand through SP surveys the relative importance assigned by travelers to various characteristics of their journey (e.g., cost to change the transport mode they used). The survey was conducted at the Atocha HSR station in Madrid, the main HSR station in Spain. It was conducted face-to-face with a questionnaire that elicited RP and SP responses.

Respondents used a paper questionnaire tailored to better adhere to the evidence of actual market behavior (i.e., HSR services), and the hypothesized scenarios. The first part of the questionnaire asked the respondents to describe their RP preferences, taking into account the current journey, and included questions on the following: $(a)$ journey origin and destination, $(b)$ journey purpose, $(c)$ journey duration, $(d)$ whether the respondent was traveling alone, $(e)$ type of ticket the respondent traveled on, $(f)$ who was paying for the journey, $(g)$ journey cost, and ( $h$ ) respondent's socioeconomic profile (income). The second part of the questionnaire was the SP exercise. A hypothetical cost scheme was briefly introduced, and the respondents were asked if they would choose another mode and which costs would influence their decisions. The cost variable varied across four levels, and those values were the same regardless of the HSR service evaluated.

The RP and SP surveys were conducted in March 2014. Of these, 220 completed RP and SP interviews focused exclusively on HSR travelers, with men $(61 \%)$ and women $(39 \%)$ chosen randomly. The key outputs of each trip maker were the following: the main socioeconomic characteristics showed that $61 \%$ of the respondents earned more than $€ 1,000$ per month. Users between 25 and 50 years old were represented the most. Forty percent of the users in the sample were singles, while $60 \%$ had partners. Most respondents (55\% of the sample) traveled with someone (i.e., with a partner or relatives), while $45 \%$ traveled alone. Fifty percent had a university degree. The sample mainly comprised employees (62\%), with lower percentages of students (18\%). For $16 \%$ of the sample, income was higher than $€ 2,500$ per month, while income was lower than $€ 500$ per month for $28 \%$ of the travelers. Finally, the three most important reasons that respondents chose HSR were the speed of the trip by train, comfort, and frequency.

With respect to journey characteristics (i.e., door-to-door), the survey results showed that HSR was the mode that required the least travel time, followed by air transport. The third shortest travel time was by car, while the coach (i.e., bus) required the longest travel time.

Although the interviews were designed to yield a higher response rate to ensure more accurate results, the respondents who provided data were a representative sample of the population that used HSR lines as described. The interviews did not allow for other analyses (e.g., of purpose, income, conventional intercity rail).

\section{Logit Model Development for HSR Service Choice}

A logit model was selected to assess strategic key variables to explain the HSR choice (e.g., price, travel time, income). The logit model predicted the choice among possible transportation mode alternatives and took into account data from each choice obtained from the survey described. The logit model considers the utility function in two parts: the part known is defined over observable characteristics $V_{j}^{m}$, and the other part $\varepsilon_{j}^{m}$ being the differences of members of the subpopulation (Equation 1).

$U_{j}^{m}=V_{j}^{m}+\varepsilon_{j}^{m}$

where

$$
\begin{aligned}
U & =\text { person's utility, } \\
m & =\text { decision maker, } \\
j & =\text { transportation mode, and } \\
V & =\text { observable characteristics of utility. }
\end{aligned}
$$

Ben-Akiva et al. claimed that early applications of discrete choice analysis used RP surveys, but SP may be used too (39). Each provides analysis and advice when data are available $(a)$ by considering one model for each case and $(b)$ by using a joint estimation method for both surveys. Indeed, implementation through a combination of RP and SP has been done in different ways, such as by valuing environmental amenities, opening new subway lines, or considering mode choice (40-42).

In addition, Hensher et al. claimed that the combination of both data sources made it possible to estimate models with data not available in one of the sources available (i.e., an alternative was present within the SP component of a data set but not within the RP component) (43). Indeed, this situation was considered previously in this research, and then field work commenced.

As suggested, the logit model was developed by considering the joint estimation of the RP and SP data, because they had complementary characteristics, and the cross-sectional survey to identify factors that otherwise would not have been known. As an illustration, to comply with the joint analysis, some researchers such as Hensher et al. proposed as a common practice to use a two-level nested logit model with one branch, including all RP alternatives, and a second branch for the SP alternatives (43). Nested logit models overcome problems detected in the single-level multinomial logit formulation as the independence of irrelevant alternatives issue. RP and SP utility functions are expressed as follows:

RP model:

$V_{\mathrm{HSR}}^{\mathrm{RP}}=\beta_{1} \operatorname{cost}+\beta_{2} T$ time

SP model:

$V_{\text {coach }}^{\mathrm{SP}}=\beta_{1} \operatorname{cost}+\beta_{2} T$ time $+\gamma_{1} \operatorname{coach}^{\mathrm{SP}}$

$V_{\text {car }}^{\mathrm{SP}}=\beta_{1} \operatorname{cost}+\beta_{2} T$ time $+\gamma_{2} \mathrm{car}^{\mathrm{SP}}$

$V_{\text {air }}^{\mathrm{SP}}=\beta_{1} \operatorname{cost}+\beta_{2} T$ time $+\gamma_{3}$ air $^{\mathrm{SP}}$ 
TABLE 2 Logit Model for HSR Services Choice

\begin{tabular}{lllcr}
\hline Variable & Alternatives & $\begin{array}{l}\text { Coefficient } \\
\text { Estimate }\end{array}$ & $t$-Statistic & $p$-Value \\
\hline Cost, $\beta_{1}(€)$ & All & -0.0212541 & $(-4.728)$ & .000 \\
Travel time, $\beta_{2}(\mathrm{~min})$ & All & -0.0049389 & $(-1.613)$ & .107 \\
$\gamma_{1}$ ASA coach-SP & Coach & -0.8315303 & $(-1.018)$ & .309 \\
$\gamma_{2}$ ASA car-SP & Car & -1.7701313 & $(-1.996)$ & .046 \\
$\gamma_{3}$ ASA air-SP & Air & -1.6246795 & $(-1.581)$ & .114 \\
Inclusive value & RP & 1.0000000 & \multicolumn{2}{c}{ Fixed parameter } \\
Inclusive value & SP & 0.74319539 & $(3.144)$ & .001 \\
\hline
\end{tabular}

NOTE: ASA = alternative specific attribute. Summary statistics: number of observations = 220;

$\hat{L}(\hat{\beta})=-229.3376 ; \hat{L}(0)=-266.4604 ;$ pseudo $-R^{2}=.14$.

where $\beta$ is vector of cost and time, and $\gamma$ is alternative specific attribute, or model preference attribute.

The nested logit model reported in Table 2 resulted from a comparison of four models, including one that may have had additional variables in the model (e.g., income level of the interviewee) and the other without these variables. The selected model is described later in this paper. The nested logit model parameter estimates were obtained with the NLOGIT software and by considering the maximum likelihood method. For the performance of coefficients, the signs and the significance of each parameter were considered.

Overall, the estimated coefficients had the expected signs, because they had a negative effect on the utility of an alternative according to economic theory. The significance of coefficients was checked through the $t$-statistic significance test (values in brackets). These values rejected in most cases the null hypothesis that the coefficient was zero with a level of $90 \%$ confidence (i.e., $p$-values). Also, in discrete choice models, it is convenient to measure goodness of fit in a way analogous to that in linear statistical models. Indeed, the likelihood ratio test-McFadden pseudo- $R^{2}\left(\rho^{2}\right)$ - provides a convenient basis to compare different models when more than one alternative is being estimated.

Although the pseudo- $R^{2}$ was analogous to $R^{2}$ in linear regressions (ranged between zero to one), it could not be analyzed in the same way and should be used with some caution. In fact, the relationship between the indices $R^{2}$ and pseudo- $R^{2}$ were provided in Domencich and McFadden (36). Within this context, several researchers suggested that pseudo- $R^{2}$ values tended to be much lower, and a pseudo- $R^{2}$ value of about 2 was good (37, 43-45). Moreover, BenAkiva and Lerman claimed that statistical tests could not be used as the only criteria for acceptance or rejection of a model (46).

In addition, the direct and cross-point elasticities in Table 3 were reported by applying the NLOGIT effects option. These values reflected the relationship between the change of cost of the alter-

TABLE 3 Direct and Cross-Point Mode Choice Elasticities for HSR Services' Choice Changing Cost

\begin{tabular}{lrrrr}
\hline Transportation Mode & \multicolumn{1}{c}{ HSR } & Coach & \multicolumn{1}{l}{ Car } & \multicolumn{1}{c}{ Air } \\
\hline HSR & -0.583 & 0.608 & 0.632 & 0.692 \\
Coach & 0.205 & -0.662 & 0.406 & 0.424 \\
Car & 0.047 & 0.088 & -0.480 & 0.102 \\
Air & 0.097 & 0.169 & 0.197 & -1.537 \\
\hline
\end{tabular}

native (i.e., HSR) and the change in demand share. For instance, given the elasticity on the train alternative, the direct effect was -0.58 , which meant that under ceteris paribus a $1 \%$ increase in train cost would decrease the probability that the train alternative would be selected by $0.58 \%$. The remaining elasticities represented the cross-elasticity effects. As explained, a $1 \%$ increase in train cost would result in a $0.61 \%$ increase in the choice probabilities for the selection of coach bus.

With these values, the direct effect of cost elasticity for the train was relatively inelastic, whereas the cross-elasticity effects of cost on the coach bus, car, and air alternatives would result in an increase of their choice probabilities. Similarly, the remaining elasticities confirmed expectations: an increase in cost was likely to increase the demand for competing goods or services. However, despite these unquestionable achievements, cross elasticities were nonetheless beset by bias in the survey answers, because the same person answered several questions about his or her journey (47).

Any comparison was difficult of the estimation results with those in the literature and project studies, because this present research focused on the demand changes experienced on Spain's HSR lines. Although the results shown in Table 3 were valid for Spanish HSR users, to conduct an accurate comparison, it would be necessary to carry out a survey for every type of traveler. Nevertheless, as will be explained further on, the elasticities found differed only in their order of magnitude but not in the expected sign.

Román et al. conducted a SP and RP survey with 3,143 valid observations for all types of users in the Madrid-Zaragoza-Barcelona corridor (48). The elasticity of HSR services with respect to price was -0.55 for the Madrid-Zaragoza route and -0.72 for Madrid-Barcelona, which was fairly consistent with the results obtained here. The cross elasticity of HSR with respect to car use was 0.12 for MadridZaragoza (0.047 in the present case study), and was 0.7 with respect to air services on the Madrid-Barcelona route (0.097) in Table 3 for the present case study. Martín and Nombela used a much bigger sample of 12,500 travelers on all transport modes to forecast the impact of HSR in the whole country (49). Airplane elasticity with respect to price was -1.216 , and HSR elasticity was -0.432 , slightly less than in the present study $(-1.537$ and -0.583 , respectively). With respect to the elasticities and cross elasticities of the remaining transport modes, all had the same sign but were lower than in the present research. There are several potential explanations for this outcome, such as changed preferences after the economic crisis or a biased sample because of the small number of respondents, to name but two.

For some pairs of European cities, Adler et al. found the direct elasticities for business users of HSR and air ranked from -0.71 to 
-0.92 (50). These direct elasticities turned out to be much higher in the case of leisure users, with a range from -1.11 to -1.94 . Matas et al. also pointed out a higher elasticity for leisure than for business travelers (51). Therefore, the high elasticities found also could be explained by a relatively high proportion of about $53 \%$ of leisure and family purpose users.

\section{CONCLUSIONS}

To foster the use of HSR and increase the occupancy rates of trains, the government of Spain reduced ticket prices by at least $11 \%$ and at the same time introduced a flexible pricing approach. This study analyzed the effects of the new tariff scheme recently implemented in the Spanish HSR system. Four main policy lessons arose from this research.

First, although users did not choose their travel mode on the basis of ticket price alone, price elasticity turned out to be high. In fact, price was identified as one of the most important reasons to travel by train, along with travel time, comfort, and mode frequency. These four factors in conjunction with Renfe Operadora's punctuality commitment made HSR regarded in Spain as a traveler-friendly mode compared with other public transportation modes.

Second, in the Spanish case, this price elasticity in the short term could be set at about 0.6 , but the effects of the new pricing approach would differ and depend on the type of corridor and the competition with other modes. In corridors in which HSR was the dominant mode, the price elasticity was lower than in corridors in which many travel options were available to users. In other words, the larger the number of travelers and the fiercer the competition was in the corridor, the greater the capability of HSR to draw users from other modes and to induce additional demand.

Third, in transport systems in which infrastructure manager and train operator companies were controlled by the government, the implementation of the new tariff approach could harm the rules of fair competition between transport modes and introduce perverse incentives (e.g., cheaper ticket for the AVE than for the bus), while the train operating companies did not cover the total infrastructure cost through fees.

Last, HS trains could replace buses and other kind of train services and compete with cars for short to medium distances, up to 400 to $500 \mathrm{~km}$. This capacity also was the case for trips under $2 \mathrm{~h}$. For longdistance journeys, competition was mainly with the airplane, whereas car use seemed not to be so affected.

\section{ACKNOWLEDGMENT}

The authors acknowledge the support of the seminar in transport economics developed by the Transport Research Center-TRANSyT of the Universidad Politécnica de Madrid, Spain.

\section{REFERENCES}

1. Betancor, O., and G. Llobet. Contabilidad Financiera y Social de la Alta Velocidad en España. Publication 2015/08. Gobierno España, Ministerio de Fomento. Secretaría General Técnica Centro de Documentación del Transporte, Madrid, Spain, 2015.

2. Renfe Bajará un $11 \%$ el Precio del Billete General del AVE a Partir del 8 de Febrero. El País, Jan. 29, 2013. http://economia.elpais.com /economia/2013/01/29/actualidad/1359460357_382996.html.
3. Morrison, S. A. Actual, Adjacent, and Potential Competition: Estimating the Full Effect of Southwest Airlines. Journal of Transport Economics and Policy, Vol. 35, No. 2, 2001, pp. 239-256.

4. Albalate, D., and G. Bel. High-Speed Rail: Lessons for Policy Makers from Experiences Abroad. Public Administration Review, Vol. 72, No. 3, 2012, pp. 336-349.

5. Givoni, M. Development and Impact of the Modern High-Speed Train: A Review. Transport Reviews, Vol. 26, No. 5, 2006, pp. 593-611.

6. OECD/ITF. The Economics of Investment in High-Speed Rail. OECD Publishing, Paris, 2014.

7. de Rus, G. The Economic Evaluation of Infrastructure Investment: Some Inescapable Tradeoffs. Documento de Trabajo 2014-16. Universidad de Las Palmas de Gran Canaria, FEDEA, and Universidad Carlos III de Madrid. Madrid, Spain, 2014. http://www.fedea.es.

8. de Rus, G., and C. Román. Análisis Económico de La Línea de Alta Velocidad Madrid-Barcelona. Revista de Economia Aplicada, Vol. 14, No. 42, 2006, pp. 35-79.

9. Sánchez-Borràs, M., C. Nash, P. Abrantes, and A. López-Pita. Rail Access Charges and the Competitiveness of High-Speed Trains. Transport Policy, Vol. 17, No. 2, 2010, pp. 102-109.

10. Preston, J. The Case for High Speed Rail: A Review of Recent Evidence. Report No. 09/128. Royal Automobile Club Foundation, London, 2009.

11. Leheis, S. High-Speed Train Planning in France: Lessons from the Mediterranean TGV-Line. Transport Policy, Vol. 21, 2012, pp. 37-44.

12. Loukaitou-Sideris, A., H. Higgins, M. Piven, and W. Wei. Tracks to Change or Mixed Signals? A Review of the Anglo-Saxon Literature on the Economic and Spatial Impacts of High-Speed Rail. Transport Reviews, Vol. 33, No. 6, 2013, pp. 617-633.

13. Monzón, A., E. Ortega, and E. López. Efficiency and Spatial Equity Impacts of High-Speed Rail Extensions in Urban Areas. Cities, Vol. 30, No. 1, 2013, pp. 18-30.

14. Bröcker, J., A. Korzhenevych, and C. Schürmann. Assessing Spatial Equity and Efficiency Impacts of Transport Infrastructure Projects. Transportation Research Part B: Methodological, Vol. 44, No. 7, 2010, pp. 795-811.

15. Chen, C.-L., and P. Hall. The Impacts of High-Speed Trains on British Economic Geography: A Study of the UK's InterCity 125/225 and Its Effects. Journal of Transport Geography, Vol. 19, No. 4, 2011, pp. 689-704.

16. Rothengatter, W. Competition Between Airlines and High-Speed Rail. In Critical Issues in Air Transport Economics and Business (R. Macário and E. Van de Voorde, eds.), Routledge, New York, 2011, pp. 319-342.

17. Vickerman, R. High-Speed Rail in Europe: Experience and Issues for Future Development. The Annals of Regional Science, Vol. 31, No. 1, 1997, pp. 21-38.

18. Dobruszkes, F. High-Speed Rail and Air Transport Competition in Western Europe: A Supply-Oriented Perspective. Transport Policy, Vol. 18, No. 6, 2011, pp. 870-879.

19. Pagliara, F., J. M. Vassallo, and C. Román. High-Speed Rail Versus Air Transportation: Case Study of Madrid-Barcelona, Spain. In Transportation Research Record: Journal of the Transportation Research Board, No. 2289, Transportation Research Board of the National Academies, Washington, D.C., 2012, pp. 10-17.

20. Behrens, C., and E. Pels. Intermodal Competition in the London-Paris Passenger Market: High-Speed Rail and Air Transport. Journal of Urban Economics, Vol. 71, No. 3, 2012, pp. 278-288.

21. Clewlow, R.R., J.M. Sussman, and H. Balakrishnan. The Impact of High-Speed Rail and Low-Cost Carriers on European Air Passenger Traffic. Transport Policy, Vol. 33, 2014, pp. 136-143.

22. Albalate, D., G. Bel, and X. Fageda. Competition and Cooperation Between High-Speed Rail and Air Transportation Services in Europe. Journal of Transport Geography, Vol. 42, 2015, pp. 166-174.

23. Chiambaretto, P., and C. Decker. Air-Rail Intermodal Agreements: Balancing the Competition and Environmental Effects. Journal of Air Transport Management, Vol. 23, 2012, pp. 36-40.

24. Pagliara, F., A. La Pietra, J. Gomez, and J. M. Vassallo. High-Speed Rail and the Tourism Market: Evidence from the Madrid Case Study. Transport Policy, Vol. 37, 2015, pp. 187-194.

25. Delaplace, M., F. Pagliara, J. Perrin, and S. Mermet. Can High-Speed Rail Foster the Choice of Destination for Tourism Purpose? ProcediaSocial and Behavioral Sciences, Vol. 111, 2014, pp. 166-175.

26. Hsu, C. W., Y. Lee, and C. H. Liao. Competition Between High-Speed and Conventional Rail Systems: A Game Theoretical Approach. Expert Systems with Applications, Vol. 37, No. 4, 2010, pp. 3162-3170. 
27. Yang, H., and A. Zhang. Effects of High-Speed Rail and Air Transport Competition on Prices, Profits, and Welfare. Transportation Research Part B: Methodological, Vol. 46, No. 10, 2012, pp. 1322-1333.

28. Harvey, J., N. Thorpe, M. Caygill, and A. Namdeo. Public Attitudes to and Perceptions of High-Speed Rail in the UK. Transport Policy, Vol. 36, 2014, pp. 70-78.

29. Cheng, Y.-H., and T.-Y. Huang. High-Speed Rail Passenger Segmentation and Ticketing Channel Preference. Transportation Research Part A: Policy and Practice, Vol. 66, No. 1, 2014, pp. 127-143.

30. Cadarso, L., Á. Marín, J. L. Espinosa-Aranda, and R. García-Ródenas. Train Scheduling in High Speed Railways: Considering Competitive Effects. Procedia-Social and Behavioral Sciences, Vol. 162, 2014, pp. 51-60.

31. Patuelli, A. High-Speed Rail: Is Competition in the Market Sustainable? An Italian case. International Research Society for Public Management, Birmingham, United Kingdom, 2015, pp. 1-18.

32. Ministerio de Fomento. Los Transportes y Las Infraestructuras: Informe Anual 2013. Ministerio de Fomento-Secretaría General Técnica, Madrid, Spain, 2014

33. Renfe Congela La Bajada de Precio Del Ave Para No Dañar a Autobús y Avión. El Economista.es., Jan. 21, 2014. http://www.eleconomista .es/interstitial/volver/cetelem/transportes/noticias/5474387/01/14 /Renfe-congela-la-bajada-de-precio-del-AVE-para-no-danar-a-autobus -y-avion.html\#.Kku8HvGDecAfd11.

34. Inglada, V. Análisis Empírico del Impacto del AVE Sobre La Demanda de Transporte en El Corredor Madrid-Sevilla. Revista del Ministerio de Transportes, Turismo y Comunicaciones, Vol. 62, 1994, pp. 35-51.

35. Vassallo, J. M., S. Awad, and J. de las Heras. Balance Económico: Fiscal, Social y Medio Ambiental del Sector del Transporte de Mercancías en España. Actualización 2012. Cátedra Amelio Ochoa. Fundación Francisco Corell, Madrid, Spain, 2014.

36. Domencich, T.A., and D. McFadden. Urban Travel Demand: A Behavioral Analysis. North Holland Publishing, Amsterdam, Netherlands, 1975.

37. McFadden, D. Quantitative Methods for Analyzing Travel Behavior of Individuals: Some Recent Developments. In Behavioural Travel Modelling (D. A. Hensher and P. R. Stopher, eds.), Croom Helm, London, pp. 279-318.

38. Anderson, S., A. de Palma, and J. Thisse. A Representative Consumer Theory of the Logit Model. International Economic Review, Vol. 29, No. 3, 1988, pp. 461-466.

39. Ben-Akiva, M., M. Bradley, T. Morikawa, J. Benjamin, T. Novak, H. Oppewal, and V. Rao. Combining Revealed and Stated Preferences Data. Marketing Letters, Vol. 5, No. 4, 1994, pp. 335-349.
40. Adamowicz, W., J. Louviere, and M. Williams. Combining Revealed and Stated Preference Methods for Valuing Environmental Amenities. Journal of Environmental Economics and Management, Vol. 26, pp. 271-292. http://www.sciencedirect.com/science/article/pii/S0095069684710175.

41. Ben-Akiva, M., and T. Morikawa. Estimation of Switching Models from Revealed Preferences and Stated Intentions. Transportation Research Part A: General, Vol. 24, No. 6, 1990, pp. 485-495.

42. Wardman, M. A Comparison of Revealed Preference and Stated Preference Models of Travel Behaviour. Journal of Transport Economics and Policy, Vol. 22, No. 1, 1988, pp. 71-91.

43. Hensher, D. A., J. M. Rose, and W. H. Greene. Applied Choice Analysis: a Primer. Cambridge University Press, United Kingdom, 2005.

44. Louviere, J., D. A. Hensher, and J. D. Swait. Stated Choice Models:Analysis and Application. Cambridge University Press, United Kingdom, 2000.

45. Oppewal, H., and H. J.P. Timmermans. Discrete Choice Modeling: Basic Principles and Application to Parking Policy Assessment. In Regional Science in Business (G. Clarke and M. Madden, eds.) Advances in Spatial Science Series, Springer-Verlag, Berlin Heidelberg New York, 2001, pp. 97-114.

46. Ben-Akiva, M., and S. R. Lerman. Discrete Choice Analysis: Theory and Application to Travel Demand. MIT Press, Cambridge, Mass., 1985.

47. Lu, H., T. Fowkes, and M. Wardman. The Influence of SP Design on the Incentive to Bias in Responses. In Proceedings of the European Transport Conference, Strasbourg, France, 2006, pp. 1-17.

48. Román, C., R. Espino, and J.C. Martín. Analyzing Competition Between the High-Speed Train and Alternative Modes. The Case of the Madrid-Zaragoza-Barcelona Corridor. Journal of Choice Modelling, Vol. 3, No. 1, 2010, pp. 84-108.

49. Martín, J. C., and G. Nombela. Impacto de Los Nuevos Trenes Ave Sobre la Movilidad. Revista de Economía Aplicada, Vol. 16, 2008, pp. 5-23.

50. Adler, N., C. Nash, and E. Pels. High-Speed Rail and Air Transport Competition: Game Engineering as Tool for Cost-Benefit Analysis. TI 2008 103/3. Discussion Paper. Tinbergen Institute, Rotterdam, Netherlands, 2008.

51. Matas, A., J.L. Raymond, M. González-Savignat, and A. Ruiz. Evaluación Económica de Proyectos de Transporte: La Predicción de la Demanda en La Evaluación de Proyectos. Cuadernos Económicos de Ice, No. 80, 2009 